\title{
Sergio Rojas
}

Universidad Nacional de Asunción - Paraguay

Asunción, Paraguay

rojasergio6@gmail.com

El caso Los Novísimos: una revolución simbólica específica en la génesis del campo artístico paraguayo

The case of Los Novísimos: a specific symbolic revolution in the Paraguayan artistic field genesis

\section{Contenido}

RESUMEN 58

ABSTRACT $\quad 58$

1. INTRODUCCIÓN 59

2. METODOLOGÍA 59

3. RESULTADOS 62

3.1 Principios de la estructuración del campo artístico paraguayo 62

3.2 La subversión herética de las reglas del campo65

3.2.1 Transformación de las posiciones $\quad 65$

3.2.2 Tomas de posición y desplazamientos $\quad 68$

4. CONCLUSIONES 69

REFERENCIAS 70

AUTOR 71

CONFLICTO DE INTERESES $\quad 71$ 


\section{El caso Los Novísimos: una revolución simbólica específica en la génesis del campo artístico paraguayo}

The case of Los Novísimos: a specific symbolic revolution in the Paraguayan artistic field genesis

Sergio Rojas

Universidad Nacional de Asunción - Paraguay

Asunción, Paraguay

rojasergio6@gmail.com

\section{RESUMEN}

El artículo presenta los hallazgos de una investigación hecha sobre el proceso de la génesis del campo artístico paraguayo y el fenómeno de grupos de vanguardia antagónicos, entre los años 50 y 6o's. Se utilizó el sistema teórico de Pierre Bourdieu, cuya puesta a prueba dejó ver que sus conceptos definen, simultáneamente, una interpretación conceptual específica y unas funciones metodológicas precisas en la reconstrucción de casos particulares: por ejemplo, mantener una perspectiva relacional, ejercer la ruptura con las prenociones y los datos preconstruidos, como también estabilizar un modelo analógico para la comparación entre casos ya establecidos. Esto significa que, si bien se estudiaron las propiedades singulares del caso, el objetivo radicó en inscribirlo en una serie de casos históricos semejantes mediante el razonamiento por analogía. El artículo presenta tres dimensiones estrictamente interrelacionadas: a) dimensión epistemológica; b) dimensión histórica; y c) una dimensión de análisis. Las proposiciones teóricas hacen inteligible que las tomas de posición de los grupos Arte Nuevo y Los Novísimos constituyeron unas específicas articulaciones entre la ética, la estética y la política en el arte paraguayo.

Palabras clave: los Novísimos; campo artístico; habitus; revolución simbólica; arte paraguayo

\section{ABSTRACT}

This paper shows the research finding of the Paraguayan artistic field genesis process and the phenomenon of the avantgarde antagonistic groups around the 1950 s and 1960s. Pierre Bourdieu's theoretical system was utilized for the purpose of construction and reconstruction: the deployment of concepts in this case showed that they define a specific conceptual interpretation and very precise methodological steps simultaneously. This means that, even if the singular properties of the case have been studied, the main aim resided in inscribing it in a series of similar historical cases through the reasoning by analogy. Furthermore, the logic of the investigation was composed of historical analysis, epistemological vigilance, and socio-analysis for the sake of reaching the rigorousness that characterizes sociology. The paper is structured by three interrelated dimensions: and epistemological dimension; a historical dimension; and a dimension of the analysis.

Naturally, the Paraguayan artistic field has displayed singular properties like a particular case. But the heuristical power of Bourdieu's theoretical propositions has allowed inscribing the Paraguayan case in the model of symbolic revolutions and in the specific struggle which revolved around the proper definition of art that was carried out by avant-garde groups. At the same time, the political context was a fundamental element: as Stroessner's power was increasing (with the support of international cooperation like Brazil or the United States contributions), local artists, writers, and intellectuals were defining the structure and the autonomy of the cultural production field. Primarily, the importance of the actions of the group called Arte Nuevo was fundamental in the relative rupture with postulates of academic art; but later, Los Novísimos' irruption played as a trigger of ethic and aesthetic investments that modified the field structure as it was emerging. Results show, on the one hand, the interrelations between ethics, aesthetic and political issues in the Paraguayan artistic field during the historical period studied and, on the other hand, the theoretical force of Bourdieu's concepts. Finally, the approach applies a dispositionalist theory to study the process of symbolic production.

Keywords: Ios Novísimos; artistic field; habitus; symbolic revolution; Paraguayan art 


\section{INTRODUCCIÓN}

Lanzarse a la construcción sociológica de un objeto en el terreno del arte arrastra consigo no sólo implicancias teóricas y metodológicas sino, antes bien y, sobre todo, desafíos epistemológicos que, se reconozca o no, terminan potenciando la imaginación sociológica en tanto ésta actúe como fuerza heurística en las operaciones de investigación. Encarar una objetivación bourdieusiana del campo artístico explota la fuerza probatoria que el razonamiento por analogía permite al combinar, en los cruces argumentativos, los materiales empíricos de los procesos experimentales con la construcción conceptual según la comparación, más rigurosa en tanto más exhaustiva, entre tipos ideales de casos históricos. ¿Qué se tiene entre manos cuando un objeto presenta propiedades que parecen fundamentar, en unas condiciones espaciotemporales distintas a las que correspondían al caso francés, la transposición de un modelo teórico como el de la "génesis del campo artístico"?

La investigación se centró en el estudio del fenómeno Los Novísimos, grupo de jóvenes artistas que irrumpió en el año 1964, pero las operaciones investigativas, tributarias de su inscripción en un marco teórico determinado, impusieron que en el abordaje del objeto se estudie de manera preliminar el estado del campo artístico paraguayo en vías de constitución durante los años anteriores con el propósito de poder comprender relacionalmente las propiedades distintivas y específicas de las acciones de los agentes. Así, una caracterización de los artistas del momento precedente (especialmente aquellos agentes nucleados en torno al grupo Arte Nuevo) y las condiciones de posibilidad para el desarrollo del arte moderno en Paraguay resulta necesaria para aproximarse a una comprensión de la emergencia del campo, trazar su estructura e identificar las posiciones de los agentes e instituciones sopesando su relativa importancia, especialmente en términos de capital simbólico. Este paso se hace ineludible no sólo por razones metodológicas, sino además considerando que, en el período histórico estudiado, años ' 50 , se inscribe el ascenso del régimen stronista que, desde luego, constituyó un factor estructurante en el espacio de los posibles del campo que aquí interesa. La complejidad de este caso resulta de la intensificación de las relaciones diplomáticas del Paraguay con el Brasil a partir del gobierno stronista, que permitió desarrollar una penetrante política cultural brasileña en distintos universos sociales locales. Especialmente resaltable es la Misión Cultural Brasileña, una institución que favoreció tanto la apertura de posibilidades artísticas, como el despliegue de determinadas afinidades entre artistas paraguayos y agentes culturales y diplomáticos brasileños; todos estos factores que ciertamente hicieron posible una relativa autonomía del campo artístico respecto al control del régimen.

Una vez esbozada la estructura del estado del campo y sus relaciones con respecto al campo del poder, el análisis se sumerge en los elementos y las acciones de Los Novísimos, señalando la formación del grupo y los rasgos del habitus de sus integrantes, así como describiendo de qué modo su inserción modificó el estado del campo artístico paraguayo. Resulta claro que es en este punto donde las herramientas bourdieusianas se explotaron en mayor medida, evaluando la potencialidad de cada una y rectificando su uso y rendimiento ahí donde se hizo necesario.

\section{METODOLOGÍA}

El sistema de proposiciones teóricas actúa aquí como una arquitectónica razonada que ordena a los vectores de conocimiento en un todo coherente cuya virtud heurística se pone a prueba intentando convertir a los múltiples conocimientos de la experiencia posible en un conjunto de hechos inteligibles, y esto asumiendo, sin dudas, que la sociología se encuentra en mejores posiciones y mejor equipada para alcanzar mayores efectos de inteligibilidad que las sencillas aseveraciones del sentido común que, al no guiarse más que por la "ilusión de la transparencia", no llegan a constituir más que una "rapsodia de conocimientos", al decir de Kant (una "filosofía crítica" parecer ser, a fin de cuentas, mucho más propicia a una teoría científica que busca ser al mismo tiempo ruptura y construcción). El andamiaje conceptual bourdieusiano permite entonces establecer una inteligibilidad comparativa entre casos históricos siempre y cuando se tenga en cuenta el control de las propiedades singulares que cada 
caso particular debe permanentemente a su inscripción en un contexto histórico no perfectamente repetible: así , y sólo así, el concepto puede adoptar su forma analógica de construir, en una serie de casos, generalidades del tipo de abstracciones tipológicas sin olvidar que contiene, al mismo tiempo, una gran carga de deixis histórica (Passeron, 2011).

Dicho lo que antecede, un principio alumbra el ritmo de trabajo que exige el enfoque teórico de Bourdieu para estudiar el campo artístico: a través de su perspectiva disposicionalista expuesta más acabadamente en sus clases sobre Manet (Bourdieu, 2017), el primer momento objetivista posibilita construir el sistema de relaciones objetivas en el que se insertan los agentes, distinguiendo tanto las posiciones como las tomas de posición, para luego hacer ver, sin considerarlos como meros epifenómenos de la estructura, las acciones específicas que aquellos despliegan en dicho espacio configurando su dinámica particular: en el juego artístico, esto habilita entonces a rastrear la razón explicativa del espacio de los posibles de los artistas a través del principio de acción de la invención bajo restricción estructural. Pero si el enfoque genético se impone, de este modo, como instrumento privilegiado para despertar los posibles enterrados por la historia, o para desmarcarse de las funciones meramente legitimadoras de otras perspectivas históricas (como aquellas que guía la ilusión biográfica y retrospectiva que concibe una vida singular al modo de un destino), obliga al sociólogo, al propio tiempo, a objetivarse a sí mismo para evitar caer preso, él también, de la amnesia de la génesis: análisis histórico, vigilancia epistemológica y socioanálisis son aquí simultáneamente herramientas de ruptura y herramientas de construcción en la tarea de reconstruir y restituir la arbitrariedad de los comienzos de los fenómenos que toma por objeto.

La noción de revolución simbólica dificulta todavía más la faena: si ella refiere a la transformación de las categorías de percepción, apreciación y división que estructuran, en la mente y en los cuerpos, el mundo social o, más específicamente, un microcosmos entendido como campo en vías de constitución, el análisis debe dar cuenta, en primer lugar, de las condiciones sociales de posibilidad que permitieron, en un momento del proceso, avanzar un quiebre de ese tipo, sin olvidar explicitar jamás, en un segundo paso irreductible a un orden cronológico, de qué se habla cuando se habla de un quiebre de la doxa (o conjunto de principios que fundamentan la adhesión tácita o la creencia en el valor del juego al interior de un campo). Fino lector de Weber, Bourdieu observó relativamente pronto que los mecanismos de creencias y profecías, de ortodoxias y herejías, propios de las religiones constituían un riquísimo material para vislumbrar una teoría materialista del poder simbólico. El devenir histórico demuestra hoy, asimismo, que la lógica del campo religioso mantiene estrechas semejanzas con la lógica del campo artístico, habilitando analogías heurísticamente potentes al estudiar, en las disputas ético-estético-políticas, las conformaciones que adoptan, en cada lugar y período histórico particulares, la distribución del capital simbólico en las relaciones agonísticas que se mantienen entre los detentores de un monopolio de los bienes de salvación o de un régimen artístico y los artistas heresiarcas, permitiendo sostener, por otro lado, que quizá la sociología del arte enfrenta hoy dificultades semejantes (no sólo epistemológicas sino además sociales) que en tiempos de Durkheim pudo haber arrostrado la sociología de la religión'.

Ahora bien, el caso particular (en el sentido bachelardiano) paraguayo posee, naturalmente, sus especificidades. Si bien es pertinente hablar de un proceso inherente a la génesis del campo artístico paraguayo (que probablemente toma poco más o alrededor de dos décadas)², también es posible encontrar en él invenciones infinitesimales que, al importar estrategias específicas al campo en ciernes, constituyen unidades significantes que permiten concluir que ellas han hecho posible una nueva configuración digna sociológicamente de una nueva descripción. La historiografía del arte paraguayo, sin embargo, ha discurrido de manera excluyente entre la vía de la ruptura o la vía de la continuidad, cuando aquí el razonamiento sociológico sostiene que ambos lenguajes se controlan articulándose para terminar alcanzando, en un zigzag científico passeroniano, mejores y más importantes efectos de inteligibilidad:

De hecho, el historiador-sociólogo debe practicar una marcha sinuosa, improvisar un paso científico en zigzag, obligándose a apoyar sus deconstrucciones y reconstrucciones sobre la investigación

\footnotetext{
1 Véase, por ejemplo, respecto al campo literario, Ponton (1973); también, y aunque con un uso ligeramente distinto de la analogía, Sapiro (2012).

2 Para unos principios preliminares que constituyen el esbozo para un estudio exhaustivo por venir del objeto, véase
} Rojas (2020, pp. 53-88). 
de discontinuidades en cuanto ve imponerse en la primera ojeada una impresión de continuidad o semejanza; y rápidamente después o simultáneamente trabajar para elaborar relaciones que no saltan a los ojos, con el fin de hacer captar una unidad de sentido o de estructura entre los rasgos más diferentes o las configuraciones históricas más alejadas. (Passeron, 2011, p. 269)

En el momento en que se percibe, entonces, un proceso histórico específico de la génesis del campo artístico paraguayo, vale decir, un espacio de relaciones agonísticas intrínsecas, se ve que el fenómeno de las vanguardias actúa movilizando también el discurso de la crisis y la ruptura, dinamizando el juego artístico en un ir y venir de acciones distintas y distintivas al propio tiempo que logra, según hace ver a posteriori la reconstrucción histórico-sociológica, mantener en marcha el trayecto procesual. Cuando emerge, al inicio del proceso, un grupo que rápidamente controla un monopolio de la competencia artística legítima o se erige en conjunto de agentes temporalmente dominantes, la aparición de otro que emplea el lenguaje de la destrucción y la crisis introduce, mediante los rasgos particulares de los habitus, propiedades que transforman toda la estructura tal como se encontraba hasta ese momento.

Se ve de qué manera la noción de campo cumple simultáneamente tanto su rol teórico como sus funciones metodológicas al exigir una perspectiva relacional, no haciendo sino explotar la concepción saussureana del valor lingüístico dentro de un sistema de diferencias (Saussure, 2007, p. 219). Dicho de otro modo, al cuestionar el monopolio de la manipulación de los bienes de salvación detentado por una ortodoxia artística y al cuestionar los principios temporalmente legítimos de evaluación, el discurso herético del último grupo transforma el espacio de los posibles y abre el horizonte del porvenir, donde la ilusión de la novedad radical permite pensar lo que hasta ese momento era impensable y todo parece ser posible para los artistas heresiarcas y los promotores del desorden sagrado. Tal es el fenómeno de Los Novísimos.

Pero los movimientos de las generaciones artísticas no agotan, ni mucho menos, la potencialidad de los conceptos bourdieusianos cuando la mirada sociológica se posa sobre el campo artístico. De hecho, si se quiere comprender algo de él, el primer paso lógico es analizar la posición que ocupa dicho campo en relación al campo del poder, aunque teniendo en cuenta siempre y fundamentalmente los efectos transcampo que genera el Estado en tanto metacampo. Es esta diferenciación la que, si sólo se sigue a lo indicado en Las reglas del arte, no se alcanza a realizar (al menos no de manera precisa), mientras que en el caso paraguayo resultó fundamental para comprender de qué manera los artistas se posicionaban en relación a un gobierno dictatorial (y no contra una Academia todopoderosa ni irritando a un influyente público burgués prácticamente inexistente en Paraguay hasta los años 60) que, al mismo tiempo que el campo se constituía, aumentaba su poder represivo sobre la base de una acumulación de capital militar y capital simbólico. Posteriormente, la construcción de las posiciones entre artistas hace ver que los envites estéticos se originan ahí: es este espacio el que lleva a cabo la transustanciación de las fuerzas externas en movimientos particulares de su lógica, invirtiendo los sentidos que poseen fuera de él; pero también su lógica ya no responde exclusivamente a los embates heterónomos, sino que su autonomía relativa permite que las tomas de posición de sus agentes sean, antes que nada, apuestas diferenciales en relación a los adversarios más próximos del campo.

Articulación entre campos, primero, luchas de disposiciones, después: estos pasos lógicos guían las operaciones investigativas que desean apropiarse de la eficacia del método comparativo, intentando captar, a un mismo tiempo, todas las propiedades del caso singular para establecerlo dentro de la serie de casos históricos semejantes, aunque no completamente equivalentes, en tanto tipos ideales. Esta explicitación de las reglas y coacciones que se han impuesto a la interpretación conceptual de la descripción histórica es la que distingue a un razonamiento sociológico bourdieusiano que, lejos de pretender vestir un mero ropaje epistemológico, estabiliza una combinación específica de componentes teóricos cuyo dominio activo es la condición de posibilidad para poner a prueba su fecundidad heurística.

En consecuencia, en la tarea de prospección empírica se ha emprendido una metodología cualitativa para el procesamiento de material archivístico y revisión de la literatura especializada dedicada al objeto en estudios anteriores. El modelo de construcción que se ha llevado a cabo en este trabajo siguió el principio metodológico de reconstruir el espacio artístico en su conjunto (a expensas de dejar líneas de puntos) a partir no sólo del material de información (periódicos, catálogos, obras, cartas, 
biografías, etc.) tal como se ha encontrado, sino desde el análisis de la condición de posibilidad de cada material en tanto contenga el riesgo de ser un material preconstruido. Por ejemplo, rehuyendo aceptar sin discusión la terminología y los problemas propuestos por los agentes implicados en el objeto y, en cambio, detectar los posibles sesgos sociales asociados a su posición, lo que ha ayudado a ejercer verdaderamente el eclecticismo racional y el politeísmo metodológico al desenterrar datos e información de archivo en el proceso de constituir un material científicamente válido (bajo riesgo de privarse del pundonor positivista).

\section{RESULTADOS}

\subsection{Principios de la estructuración del campo artístico paraguayo}

Con el gobierno de Alfredo Stroessner, que accede al poder en el año 1954, Paraguay intensificará con Brasil unas relaciones diplomáticas que conjugaban estratégicamente intercambios culturales sobre la base de intereses económicos y políticos específicos. El ámbito artístico brasileño tomaba forma con las aperturas del Museu de Arte Moderna de São Paulo (MAM-SP), el Museu de Arte Moderna de Rio de Janeiro (MAM-RJ) y el Museu de Arte de São Paulo (MASP), que se encontraban dentro de un programa cultural impulsado tanto por el sector público como privado para impulsar a Brasil, en alianza con Estados Unidos, como un Estado progresista inmerso en un proceso desarrollista (García, 2008). En ese sentido, el país brasileño exportaría una gran maquinaria cultural a los demás países de la región a través de la instalación de la Misión Cultural Brasileña. En Paraguay, un ejemplo de la incursión de la Misión en el círculo de artistas plásticos representa el apoyo otorgado al I Salón Independiente, organizado en 1958, acontecimiento que emergía de un incipiente subcampo de producción restringida. Por otro lado, respecto al polo tradicionalista y más heterónomo, la alianza entre la Misión y entidades gubernamentales para la promoción de actividades culturales puede ser ejemplificada con diferentes casos: el Salón de Otoño, en 1958, con las obras del Museo Nacional de Bellas Artes y Antigüedades del país, el Salón Nacional de Artes Plásticas, organizado por el museo citado y el Ministerio de Educación y Cultura de Paraguay, que también contó con la participación de miembros de la Misión, y el Salón de Primavera, que en 1959 exhibió además el acervo del Museo de Arte Moderno de São Paulo, con la presencia del presidente Stroessner, embajadores y ministros (Nepomuceno, 2013; García, 2014). Más significativo aún, estas acciones originadas desde la política diplomática de Itamaraty tenían como uno de sus objetivos construir el clima propicio entre los gobiernos paraguayo y brasileño para ejecutar conjuntamente el proyecto de la Hidroeléctrica Itaipú, teniendo como uno de sus misioneros al artista brasileño Livio Abramo, un agente protagonista del proceso de modernización de las artes plásticas paraguayas ${ }^{3}$.

A esta cooperación brasileña, que también incluía acuerdos económicos y construcción de infraestructura (como el Puente de la Amistad), se sumó la alianza del gobierno stronista con Estados Unidos, adoptando la Doctrina de Seguridad Estadounidense que, equipamiento armamentístico y entrenamiento técnico mediante, enfatizaba el uso de la seguridad y las Fuerzas Armadas para "combatir la amenaza comunista". Estos acuerdos bilaterales condicionaron favorablemente la acumulación de capital económico y capital militar del gobierno de Stroessner, permitiendo crear una apariencia de "paz y progreso" y reprimir cualquier tipo de disidencia política4. Los movimientos a nivel del campo del poder recaían, sobre todo, en las disputas entre facciones del partido Colorado y la instrumentalización de las Fuerzas Armadas al servicio del mantenimiento del orden político, extendiendo unas relaciones de poderes que penetraban y condicionaban los diversos espacios de la sociedad paraguaya de esta época a partir del control del Estado en tanto metacampo. A diferencia del caso francés, no existía aquí una gran burguesía que actuaba de público real e influyente en las tomas de posición artísticas -lo cual no excluyó rechazos éticos y simbólicos respecto a modos de vida considerados burgueses-, como tampoco una sólida Academia que, en tanto cuerpo, estuviera en condiciones de imponer un conjunto de principios y puntos de vista instituidos fuera del cual fuese impensable la consagración artística. Estas diferencias, que ya delinean un proceso de constitución del campo relativamente distinto (pero de ningún modo anulan el modelo teórico, sino que acentúan el carácter ideal-típico de la descripción conceptual en las

3 Sobre esto, véase Quevedo (2018, pp. 130-136).

$4 \quad$ Para un primer acercamiento al respecto, véase Nickson (2011). 
ciencias históricas), son las que han favorecido un claro fortalecimiento del subcampo de producción restringida (integrado, fundamentalmente, por productores que deben su reconocimiento al juicio de sus pares), en detrimento, o en un ritmo diametralmente opuesto durante esta etapa, del subcampo de gran producción: en primer lugar, porque no existía un mercado comercial del arte paraguayo ni un público burgués dispuesto a pagar grandes cantidades de dinero por obras de arte ${ }^{5}$; en segundo lugar, porque la situación política de control estatal y represión propiciaba la autonomización de un espacio desde el cual poder pensar y plantear acciones artísticas de disidencia política. En una palabra, el campo se va estructurando en la forma de una antieconomía en dos frentes: contra la economía económica y contra la economía política.

En efecto, debido a la administración de Albino Peixoto (durante el período 1952-1958), que estrechó relaciones con intelectuales, escritores y artistas paraguayos, en su mayoría opositores al gobierno, en lugar de acercarse a la oficialidad del régimen militar, la Misión Cultural Brasileña se convertiría en un espacio que promocionaba la creación artística independiente y, sin duda, contribuiría al fortalecimiento de la autonomía del campo artístico paraguayo en vías de constitución. El sentido de dicha "creación artística independiente" sólo puede entenderse en relación al desarrollo de las artes plásticas paraguayas y a la concepción de la creación artística que, hasta estos años, estaban representados mayoritariamente por la idea de la ejecución y copia de un modelo dictado por los "maestros", cuya formación, en mayor o menor medida según cada caso, se constituía de cierto esquema y contenido académicos obtenidos en el exterior (en países como Argentina, Francia o Italia). Los postulados académicos incluían, entre otros, el del "realismo representativo" y el uso de los recursos naturalistas en las obras de paisajes ${ }^{6}$. Entre los agentes más representativos de esta posición denominada tradicionalista se podría mencionar a Roberto Holden Jara, Jaime Bestard y Pablo Alborno.

Las bases y las vías para la influencia cultural brasileña ya se encontraban en marcha durante los primeros años de la década del 50, y es en 1953 cuando el Paraguay fue invitado por primera vez, a través de la Misión Cultural Brasileña, a participar en la II Bienal de São Paulo, realizada en diciembre del mismo año. La selección de artistas para la representación paraguaya fue encargada al Centro de Artistas Plásticos Paraguayos (CAPP), cuya presidencia era ejercida por Roberto Holden Jara. El proceso de selección originó la disputa de dos sectores opuestos; por un lado, el llamado tradicionalista (que intentaba conservar los esquemas académicos y ya clásicos) y por el otro un sector que buscaba la introducción de lenguajes estéticos renovadores o, aún más importante, que apuntalaba la práctica artística desapegada de la ejecución de un modelo y la afirmación de la "creación independiente" de cada artista.

El enfrentamiento explícito contra la creación artística sujeta a la copia de un modelo y a los postulados académicos se desata durante los primeros años 50 y se consolida con la creación del grupo Arte Nuevo, conformado originariamente por Olga Blinder, Josefina Plá, Lilí del Mónico y José Laterza Parodi. Los cuatro integrantes poseían, en su conjunto, características sociales que los hacían sufrir las contradicciones inherentes al estatuto de "parientes pobres de la burguesía", pero que, conforme a una estrategia históricamente frecuente de los grupos estigmatizados, emplearon para lograr transformar el estigma en bandera (Rojas, 2020). A través de las disposiciones particulares de estos agentes, se inicia la instauración, en este estado del campo en formación, del rechazo simbólico a las comodidades del "sector selecto de la sociedad" asociadas a lo burgués y a los convencionalismos tradicionales del arte académico de la generación anterior que, con su "vocabulario gastado de paisajes y retratos asépticos" (Escobar, 2007, p. 384), encarnaban una especie de “negación de lo social”. El péndulo se orienta, entonces, a manifestar por intermedio de las nuevas formas realidades locales y políticas como búsqueda de identidad, al mismo tiempo que la generosidad subjetiva que permite la "proyección de uno

\footnotetext{
$5 \quad$ Existe y se sostiene la hipótesis de que, con las transformaciones económicas en la estructura social paraguaya desde la década del 70, este subespacio se desarrolló. El proceso completo de constitución del campo artístico paraguayo abarca un período más largo que el tratado aquí, pero una investigación más amplia y por venir dará cuenta de ello.

6 Dentro de estos lineamientos se encontraron características “impresionistas", "posimpresionistas”, entre otras, para la caracterización de artistas de este período. Para una inspección más detallada de los elementos estéticos que podrían considerarse diferenciadores, véase Escobar (2007, pp. 347-382). Las comillas tienen la función de, cuando menos, evitar tomar estos conceptos estéticos como conceptos deshistorizados y reificados. Gran parte de estos conceptos fueron en su génesis y en sus usos posteriores instrumentos de lucha y esquemas clasificatorios de artistas, críticos, historiadores del arte, etc., con efectos simbólicos muy específicos (Bourdieu, 2017, p. 267).
} 
mismo en el otro", completamente falsificante desde el punto de vista sociológico, comienza a rendir beneficios simbólicos idealizando las condiciones de vida de las "clases populares". Ante la indagación de un médico por la elección de sus temas, Olga Blinder respondía:

¿Por qué él pensaba que yo sólo tenía que pintar mi realidad? Y además, esa también era mi realidad porque la veía; me iba al mercado y veía a esas mujeres. Pintaba eso porque me llegaba, porque sentía la angustia de esas mujeres (Blinder, 2004, p. 168).

Estos virajes lejos están de originarse en una verdadera relación con las "clases populares", sino que constituyen, antes que nada, posiciones distintivas en relación a los demás agentes miembros del campo de producción artística, favoreciendo los alejamientos o acercamientos entre pares y la calibración de la legitimidad que confiere, en un estado particular del campo intelectual, erigirse como portavoz de aquello denominado "pueblo". Pero la expresión por excelencia de la contradicción y culpa vividas por escritores y artistas en su posición estructuralmente dominada frente a la burguesía y relativamente dominante hacia las clases bajas, la brinda Augusto Roa Bastos, alrededor de la misma época7:

Yo soy burgués, o al menos pertenezco por mi extracción a la clase pequeñoburguesa; pero la única posibilidad que tengo de liberarme de ese molde social caduco es sublevándome contra él para acercarme a la masa de oprimidos. No me puedo jactar de pertenecer a la clase de los opresores; no es un orgullo serlo; pero tengo que hacer algo para redimirme de su estigma y afirmar mi deseo de liberación (Roa Bastos, 1960, p. 4).

Este tipo de afirmaciones lograba consolidar un nomos específico del campo, alentando, ciertamente, la creación artística con formas estéticas más modernas, pero vehiculizaba a la vez una "responsabilidad social" del arte con principios humanistas ${ }^{8}$ e impulsaba la "búsqueda de la raíz", tan cara a Josefina Plá. Sumado a esto, los editoriales de la revista Alcor ${ }^{9}$, en números sucesivos de la década del 50 y 60, exhortaban a intelectuales, literatos y artistas a posicionarse políticamente a través de sus obras. Dentro de este espacio de posibilidades del campo es como deben entenderse las acciones de Olga Blinder, quien, mediante sus disposiciones de militante de izquierda que conformaban parte de los rasgos de su habitus, ejerce una toma de posición específica con la obra Los torturados (1963), serie de xilografías que integra tanto la creación artística con formas modernas como la manifestación de la realidad política nacional en oposición al poder político oficial del régimen stronista. Esta obra, sin embargo, es la culminación de un período que gracias al trabajo artístico y pedagógico (como en la Escolinha de Arte, de la Misión Cultural Brasileña) de Blinder, junto con el peso de consagración de Plá, se definió a la primera como profeta ejemplar, en el sentido de Weber, y permitió al original grupo Arte Nuevo nuclear a su alrededor a un creciente círculo de escolares, adeptos y compañeros unidos mediante una adhesión personal, conformando posteriormente una congregación que, con la acumulación progresiva de capital simbólico específico y capital social, detentaría el monopolio de la legitimidad artística y el control de los circuitos, locales e internacionales (sobre todo en Brasil), de exhibición: "La transformación de la adhesión personal en una congregación constituye la forma normal en que la enseñanza del profeta pasa en la vida cotidiana a ser una función de una institución permanente" (Weber, 1992, p. 366).

Sin embargo, debido a las manifestaciones ambivalentes que estos agentes manifestaban hacia

\footnotetext{
$7 \quad$ Los históricos intercambios entre escritores y artistas en la constitución de campos autónomos de producción cultural justifican esta ampliación metodológica de los límites del objeto para una mayor fecundidad del análisis, ya que, si éste se reduce a "artistas" reificados como tales por la historiografía, no se llega a hacer inteligible en qué medida unos y otros han debido establecer estrategias hasta constituirse en campos diferenciados. Manténgase esto en mente, más adelante, para el fenómeno literario Pratt Mayans. Véase, sobre esto, Bourdieu (2015, pp. 201-209; 2017, p. 176).

$8 \quad$ Un examen más atento del artículo "Arte Contemporáneo", de Josefina Plá, devenido ya en una especie de texto sagrado de la historia del arte paraguayo, demuestra la proyección humanista de Plá sobre el arte y su disposición intelectualista, según la caracterización de Weber; véase Rojas (2020, p. 75-77).

$9 \quad$ Esta revista fue fundada en diciembre de 1955 por el poeta Rubén Bareiro Saguier y el promotor cultural Julio César Troche. En sus dos primeros números apareció bajo el nombre de Cuenco, y a partir del tercero (abril-1956) con el nombre de Alcor hasta el último número (47-trimestre 1-1969). Con gran peso simbólico en el ámbito intelectual de la época, ella articulaba a artistas, literatos, poetas e intelectuales que, en general, compartían principios modernistas similares (lo cual no implica que ocupaban las mismas posiciones).
} 
el "pueblo" y a la responsabilidad asumida de comunicar contenidos sociales, como también a sus condiciones sociales que determinaban una especie de necesidad artística con aspecto ético-rigorista, serán recién Los Novísimos quienes lleven el esteticismo hasta sus últimas consecuencias y conquisten la definitiva ruptura entre el arte y la moral.

\subsection{La subversión herética de las reglas del campo}

\subsubsection{Transformación de las posiciones}

Llegados los primeros años de la década del 6o, el grupo Arte Nuevo representaba ya la posición de vanguardia consagrada dentro del subcampo de producción restringida. Si bien para estos años ya se habían desplegado los principios fundamentales que configurarían la estructura del campo artístico paraguayo en vías de constitución, tales como la negación de lo comercial y el rechazo de los esquemas conservadores del "sector selecto de la sociedad", trazando un espacio determinado de los posibles, fueron Los Novísimos quienes emprenderían sus acciones explotando toda la potencialidad de una dimensión fundamental de las rupturas estéticas: la ruptura ética. El grupo fue fundado por William Riquelme, quien integró, en tanto alianzas estratégicas, a Ángel Yegros, José Antonio Pratt Mayans y Enrique Careaga. Ejemplo paradigmático de habitus isomorfos ${ }^{10}$, las disposiciones aristocráticas que encarnaban los integrantes de Los Novísimos los llevaban a alejarse por igual tanto de los partidarios del arte con responsabilidades sociales y humanistas como también de los defensores de los postulados academicistas, percibiendo, dentro del margen de maniobra posible, la posición por crear en un movimiento que a la vez que integra toda la historia del desarrollo del campo hasta ese momento, sitúa su propósito en relación a la culminación de esa historia pero superándola:

(...) si el campo tiene una historia orientada y acumulativa, significa que el propio propósito de superación que define en sí misma a la vanguardia es a su vez la culminación de toda una historia y que se sitúa inevitablemente respecto a lo que pretende superar, es decir respecto a todas las actividades de superación que ahora están metidas en la estructura misma del campo y en el espacio de los posibles que impone a los recién llegados (Bourdieu, 2015, p. 360).

Pero el caso que hace ver más explícitamente los principios fundamentales del resorte ético y estético de Los Novísimos se halla en la premiación de la obra literaria de Pratt Mayans, pocos meses antes de la primera muestra conjunta del grupo. En 1963 el diario La Tribuna organizó un concurso literario cuyo premio había sido dividido y otorgado a Francisco Pérez Maricevich, por su cuento Guitarra al amanecer, y a Pratt Mayans, por su trabajo Pavel que suscitó uno de los más sonados escándalos en el ámbito cultural paraguayo de esta época. En el cuento Pavel, Pratt emprende una alteración de los presupuestos corrientes de la dimensión temporal involucrados en la experiencia convencional del tiempo a través de una manipulación de la cronología que, sin duda, había echado por tierra los principios de la estructura convencional del relato, así como también, mediante el recurso del estilo indirecto libre, se introduce en la conciencia de sus personajes adoptando el punto de vista situado en la práctica misma, con sus contratiempos, retrocesos y olvidos. Los cuentos de Pratt constituyen un antídoto contra las formas convencionales de la narración, como la biografía o los relatos históricos basados en la concatenación de acciones individuales pretendidamente deliberadas y voluntarias, y representan, a su vez, un planteamiento del modo de entender el habitus: estructuras estructuradas por imposiciones estructurales que, basadas en la identificación y reconocimiento de estímulos condicionales y convencionales, pueden adoptar la forma de estructuras estructurantes y engendrar estrategias para la acción, pero sin la necesidad de la exposición explícita de fines ni del cálculo racional:

El habitus como sentido práctico que es fruto de la incorporación de las estructuras del mundo social -y, en particular, de sus tendencias inmanentes y de sus ritmos temporales- engendra unos presupuestos (assumptions) y unas anticipaciones que, al estar corrientemente confirmadas por el curso de las cosas, fundamentan una relación de familiaridad inmediata o de complicidad ontológica, totalmente irreductible a la relación entre un sujeto y un objeto, con el mundo familiar

10 Para una reconstrucción más exhaustiva de las propiedades que constituyen el habitus de cada integrante y que permite sostener lo indicado más arriba, véase Rojas (2020, pp. 94, 105-110). 
(Bourdieu, 2015, p. 478-479).

Aquí radican las diferencias éticas y estratégicas esenciales que posicionarían distintivamente a Los Novísimos en relación al grupo anterior: es innegable que la ruptura con la tradición academicista la llevó adelante (al menos de manera manifiesta) el grupo Arte Nuevo, pero las disposiciones particulares de Los Novísimos harían estallar por todos los rincones del campo el desparpajo del esteta, cuyas experimentaciones artísticas explotarían el principio de jerarquización interna del campo en formación. Lejos de aquel espíritu de seriedad, de acciones militantes y en las antípodas de concebir la actividad artística como una responsabilidad con los sueños humanistas basado en un programa y una consigna, Los Novísimos afianzarán en el campo artístico paraguayo -a través del abandono de un punto de vista fijo y central en beneficio de un espacio de acciones yuxtapuestas, dinámicas y carentes de un punto de vista privilegiado, la indiferencia hacia las exigencias de la política y el desapego absoluto del ojo del artista aunado al rechazo de todo compromiso con el "pueblo"- un principio fundamental de sus acciones vanguardistas: la revolución estética sólo puede realizarse estéticamente. Es esto lo que hace explícito Pratt Mayans, quien, concibiendo su obra literaria como una realidad más autónoma sin más referente que ella misma y rechazando, al negar cualquier trascendencia del significado en relación al significante, comunicar cualquier tipo de contenido social, contribuye a constituir al personaje social llamado artista en tanto sujeto de su propia creación:

Periodista de La Tribuna: ¿Revela usted en sus cuentos vivencias personales?

Pratt Mayans: De ninguna manera. Mis cuentos son meras invenciones o creaciones puras.

(...)

PLT: ¿Cuál es el tema?

PM: La enajenación progresiva.

PLT: ¿Qué quiso decir con su cuento?

PM: Absolutamente nada. (Pratt Mayans, 1964)

El escándalo sulfúreo provocado por el trastocamiento de los principios de visión y división pertrechado por Pratt Mayans en sus cuentos suscitó la toma de posición histórica de los escritores y artistas más decididamente autónomos del campo de producción cultural, reivindicando la "absoluta libertad del creador" en relación a cualquier tipo de exigencias o imposiciones de fuerzas heterónomas al principio específico de la ley fundamental de independencia respecto a los poderes económicos o políticos, firmando colectivamente una declaración titulada Sobre la libertad de creación (Alsina et al., 1964). Al mismo tiempo, la extraordinaria acumulación de capital simbólico por parte de Pratt Mayans, como la afinidad de esquemas de percepción acerca de la creación artística y los límites estéticos, impulsó a William Riquelme a integrar al primero en el grupo Los Novísimos de cara a la "exposición revolucionaria" de mayo de 1964. En esta primera exposición, hecha en la tienda de ropa Martel (ubicada en el centro de Asunción y una de las más importantes y concurridas en esa época), Los Novísimos hicieron explícito su ingreso al campo artístico en ciernes; sin embargo, es el reconocimiento de los demás miembros, consagrados, especialmente, el que habilita o no la existencia de los recién llegados. En efecto, Olga Blinder se erige como poseedora del monopolio de los bienes de salvación, salvaguardando una ortodoxia artística cuyo soporte pedagógico desembocó en un desgaste del efecto de ruptura de las primeras acciones del grupo Arte Nuevo", para invertir su capital simbólico acumulado y posicionarse como artista de la vanguardia ya consagrada en la estrategia de imponer su propio punto de vista como fundamento primero de la definición legítima del "artista auténtico":

(...) es muy alentador ver que cuatro jóvenes voluntades realizan sus experiencias pictóricas y las muestran a los ojos no siempre benevolentes del público. Y sería mucho más alentador aún saber que esos cuatro jóvenes siguen trabajando, y que también se proponen estudiar y conocer, puesto que el artista no puede permitirse el lujo de improvisar en la ingenua creencia de que todo lo que

11 La virtud heurística de operar con la analogía entre la lógica del campo religioso y la lógica del campo artístico hace percibir esta propiedad del enfrentamiento entre grupos antagónicos: “Toda secta exitosa tiende a devenir Iglesia, depositaria y guardiana de una ortodoxia, identificada con sus jerarquías y con sus dogmas, y destinada, por ello, a suscitar una nueva reforma" (Bourdieu, 2006, p. 65). 
hace va a salir bien. Estos jóvenes no tienen la base de conocimientos que tal vez tendrían en otras ciudades de más movimientos artísticos, por eso aquí un joven a los veinte años no puede saber tanto de Arte como si viviera en Buenos Aires, por ejemplo, y por eso, también, aquí debemos imponernos un trabajo mucho más arduo, para suplir así las deficiencias del medio (Blinder, 1964, p. 12).

Lejos de cualquier subordinación a las orientaciones pedagógicas de los talleres de arte de la época, Los Novísimos apuntalaban, en distintas medidas según cada integrante, una estética práctica que, a través de la movilización de una cultura artística interiorizada y liberada de los discursos de escuela, explotaba las posibilidades de un acto de creación disposicionalista: entregados en cuerpo y alma a su tarea frenética, la influencia de la action painting es aquí más que una metáfora y el dripping acentúa la tensión corporal activa y constructiva y "la mano se libera completamente de toda directiva visual" [Deleuze, 2007, p. 111) ${ }^{12}$, indiferentes a las exigencias de la política y los mandamientos de la moral y los sueños humanistas, Los Novísimos acelerarán el proceso de consolidación de la autonomía del campo artístico acompañada de un movimiento de retroceso reflexivo y crítico sobre la obra de arte y sus propios presupuestos hasta someterla casi a la burla de sí misma, despliegue de la insolente desenvoltura del grupo y, también, del "espíritu iconoclasta” de la década del '60 (Escobar, 2007). No se tarda en comprender, teniendo en cuenta la estructuración sincrónica del estado del campo de este momento, los motivos que impulsaron la reacción de Olga Blinder:

Los poseedores del monopolio de la manipulación de lo sagrado, letrados de todas las iglesias, nunca son demasiado indulgentes con aquellos que pretenden "descubrir en ellos mismos las fuentes de la autoridad tradicional” y acceder sin intermediarios al depósito que tienen en custodia: como bien lo muestra Gershom Scholem, ponen siempre "tantas barreras como pueden ante los pasos del candidato al camino místico (...) y cuando las barreras llegan a asustar al peregrino y a forzarle a contentarse con la antigua ruta, porque las nuevas se le han hecho inaccesibles, tanto mejor va desde el punto de vista de la autoridad" (Bourdieu, 2012, p. 96).

Sin embargo, la insolente herejía no quedó sin respaldos: en un sector del subcampo de la crítica, la posición homóloga a la posición de Los Novísimos en el subcampo de producción pura la ocupaba el crítico de arte Óscar Trinidad, cuya toma de posición otorgó la existencia plena del grupo en el campo, transformando así el espacio de los posibles. Una crítica de arte, por muy negativa y violenta que fuere, puede contribuir paradójicamente a la producción de la obra: si bien remarca deficiencias formales y técnicas de cada uno, ofreciendo al mismo tiempo soluciones posibles a ellas, la crítica de Trinidad contribuye a la realización plena del grupo al interior del campo a la vez que se produce a él mismo como crítico de vanguardia, subrayando el silencio por parte del resto de los críticos, lo cual es una de las estrategias para impedir el ingreso al campo a una obra o a un artista, negándole el reconocimiento:

Ante la lamentable ausencia de una valoración crítica de las obras expuestas en las fechas patrias en un salón comercial de nuestra capital, creemos indicado exponer nuestras conclusiones a la misma en la convicción de que una oportunidad como la mencionada -que debiera ser factor determinante a una valoración de la que pudieran surgir conclusiones dada su poca frecuencia- sólo sirve para demostrar la escasez del elemento cultural crítico, imprescindible a todo arte, en los medios de difusión cuyo pronunciamiento es fundamental a la prosecución de eventos como el realizado. (Trinidad, 1964).

Estas luchas simbólicas tienen el propósito de establecer principios de clasificación que, lejos de ser trascendentales o universales, se trata de formas de clasificación históricamente constituidas y asociadas a condiciones históricas de producción elaboradas a través de agentes sociales que no son sólo partículas dentro de un campo gravitacional sino portadores de estructuras cognitivas con

12 Dentro de lo que se ha llamado "expresionismo abstracto", la action painting (pintura de acción) y el dripping (chorreado de pintura sobre la tela puesta en el suelo) eran técnicas que permitían romper con el cuadro de caballete, incorporar nuevos materiales como el barniz al aluminio, esmaltes sintéticos, etc., y acentuar la carga gestual y el dinamismo al involucrar no sólo las manos del artista sino todo el cuerpo. 
capacidades de agencia. Así, invenciones infinitesimales que marcan rupturas coadyuvan al mismo tiempo a la configuración específica de una transición de mayor duración. Tan sólo por las necesidades del análisis, se separan, en este punto, dos dimensiones, pero, en realidad, el objeto hace inevitable un círculo hermenéutico casi permanente entre la información obtenida de las posiciones y la información proporcionada por las obras.

\subsubsection{Tomas de posición y desplazamientos}

Ahora bien, en el espacio de las tomas de posición -aquí, de manera más precisa, en la escala de las obras-, Los Novísimos emplearon armas específicas para la conversión ética y estética de los artistas en su liberación no sólo respecto a la política económica y la economía política, sino también en la superación de la inicial subordinación estructural en sus relaciones con los críticos de arte, en tanto profesionales de la explicitación y el discurso. En una obra de 1964, Careaga recurre al dripping e inserta la propia expresividad y la carga gestual a la pintura llevando mucho más lejos la disociación de posiciones entre el acto de pintar y el acto de observar, ya que el primero coloca el soporte sobre el suelo mientras que el segundo ve la obra expuesta en vertical, invirtiendo el espacio óptico entre un momento y otro ${ }^{13}$. Con la abstracción no sólo se eleva el grado de autonomía del espacio estético de la obra sino que, con la acción práctica pictórica de Careaga y el nivel propiamente pansémico de la pintura abstracta, se explota y reivindica aún más la autonomía y libertad del artista, buscando desprenderse de la inferioridad estructural inicial respecto al crítico o al literato, al tiempo que los títulos oscuros o directamente la ausencia de ellos limitan la posibilidad del metadiscurso o de la narración, y todo ello sin terminar, simultáneamente, alimentando la producción de la creencia y la posibilidad de todos los discursos posibles que la pintura ofrece a la divagación subjetiva del espectador:

Considero la pintura una manifestación intrascendente. Ningún trazo hecho por la mano del hombre es gratuito, por tanto, el público y la crítica son dos factores ajenos e innecesarios. El artista realiza su obra por exigencia íntima. El valor de la obra es “a priori” a su conclusión y radica en la misma exigencia de la realización de ella. Concluida la obra, ésta ya no tiene importancia para el artista, puede incluso ser destruida, porque ya cumplió su cometido, cual es el de servir de liberación última. Por eso digo que el público y la crítica ya carecen de importancia, porque lo único que a ellos les resta por hacer, es la disección de un cadáver (Careaga, 1964).

Al negarse a servir a las buenas causas y a someterse a cualquier tipo de demanda (sea económica o política), Los Novísimos explotan, en la fase inicial de acumulación simbólica, todas las apariencias del desinterés, conciliando a un mismo tiempo el antiutilitarismo y la división entre el arte y el dinero, la indiferencia y el desprendimiento acerca de cualquier tipo de justificación social del arte, contribuyendo con esto a la consolidación de esta particular economía de los bienes simbólicos que más bien cabría considerar como una economía antieconómica. En este sentido, al ser la ley del campo la denegación de la economía y el rechazo del arte subordinado a condiciones externas aquello que estructura el espacio y orienta los fenómenos, William Riquelme transforma este efecto de estructura en efecto de estrategia colocando a Jacinta, personaje inspirado en un prostíbulo que se localizaba próximo a la agencia publicitaria de su padre, en el espacio de las obras. Si bien este personaje apareció en distintos escenarios, en esta obra citada se evoca a una prostituta desnuda y desidealizada -ni maternal ni sufriente ni pudorosa como, atendiendo al espacio de los posibles, podía verse, por ejemplo, en obras de Blinder-, en correspondencia a su postura ética de desapego y alejada de todo sentimentalismo o erotismo. Pero, y, sobre todo, la obra ejerce otro tipo de golpe simbólico en relación a la ley fundamental del campo artístico: mediante sus rasgos caricaturescos, Jacinta se mofa del argumento esgrimido contra Los Novísimos, que fue el de haber cedido al camino de la moda o de lo fácil, idea asociada siempre a la prostitución y propiedad invariable del campo artístico ${ }^{14}$.

Los Novísimos representó desde su irrupción, y en un período de tiempo relativamente breve, el punto de tensión en el campo a partir del cual un artista que aspirase a las posiciones de vanguardia podría

\footnotetext{
13 Esta es una aguda observación que sugirió Anne Querrien a Deleuze a propósito de Pollock (en Deleuze, 2007, p. 112).

14 Dos ejemplos de las asociaciones entre la prostitución y lo comercial en el campo artístico pueden verse en las declaraciones de otros artistas de la época como Carlos Colombino (1964) y Bernardo Krasniansky (1975).
} 
impulsarse y diferenciarse. Al reconocérsele la existencia en el campo, tanto por las críticas como por la participación en la II Bienal Americana de Córdoba, así como gracias al apoyo de otros artistas ya reconocidos en este estado del campo como Hermann Guggiari, Edith Giménez o Lotte Schulz, la acumulación inicial de capital simbólico favoreció el acercamiento y la acogida de artistas con disposiciones diferentes (Yustman, Migliorisi, Grillón, entre otros) pero cuya solidaridad afectiva se asentaba sobre todo por sus intereses momentáneamente próximos, como el de acceder a posiciones distintivas y de avanzada dentro del campo, al tiempo que, por el otro lado, los miembros del grupo Arte Nuevo como Blinder, Plá y Laterza Parodi se veían empujados a ofrecer algunas concesiones al público mediante muestras en las que exponían obras menores a precios reducidos (Blinder, Plá y Laterza, 1964).

De hecho, Olga Blinder había expresado, ya casi a finales de su vida, una cuestión referida a Los Novísimos que refleja este desplazamiento: "Estaban en contra nuestra, así como nosotros estuvimos en contra de los viejos: para ellos nos habíamos convertido en los viejos, porque la velocidad de la aceleración del cambio es mucho mayor" (Blinder, 2004, p. 218). Más allá del caso particular o, precisamente, lo que el caso particular estudiado aquí deja ver, siempre que se tengan en mente las proposiciones teóricas, a través de la declaración de Blinder es una de las propiedades fundamentales del campo artístico: si el grupo Arte Nuevo alcanzó una posición consagrada gracias a y mediante la asumida lucha contra el grupo denominado tradicionalista en la década del '50, instauró con ello el modelo de la revolución y la ruptura, sobre todo manifiesta, como condición de acceso y existencia al campo. Dicho de otro modo, la lucha se instituyó en el fundamento del campo como sede de envites por el monopolio de la legitimidad artística, teniendo como resultado la imposibilidad de que nadie en él que acepte las reglas del juego pueda erigirse como dueño absoluto del nomos, ley que Los Novísimos aprehendieron con perspicacia:

\footnotetext{
Cada revolución que triunfa se legitima a sí misma, pero legitima también la revolución como tal, aun en el caso de la revolución contra las formas estéticas que ella impuso. Las manifestaciones y los manifiestos de todos aquellos que, desde principios de siglo, tratan de imponer un régimen artístico nuevo, designado con un concepto en -ismo, dan fe de que la revolución tiende a imponerse como el modelo del acceso a la existencia en el campo (Bourdieu, 2015, p. 191).
}

Pero la distinción analítica de las diferencias entre un grupo y otro es crucial y de ningún modo sus estrategias deben compararse como equivalentes, ya que ello llevaría a incurrir en el error (y no pocos intentos pasados, consciente o inconscientemente, han incurrido en ello) de definir como carencias lo que en realidad constituían armas en la lucha por la diferenciación y la legitimidad artística. Las conclusiones de la objetivación sociológica imponen su pertinencia para la realización de dicha tarea.

\section{CONCLUSIONES}

Que el análisis sociológico revele que las potencialidades del espacio de posibles se encontraban ya, en cierta medida, en estado virtual en la tradición o el momento anterior a Los Novísimos no excluye que el discurso herético haya suministrado las claves para desvelar lo que hasta ese momento era impensable porque permanecía en el estado de lo todavía no dicho, ya que la ilusión de la novedad radical que arrastra el lenguaje de la crisis y la destrucción tiende a abrir el porvenir donde todo parece ser posible: por su sola existencia, Los Novísimos discutieron, con la ambición de satisfacer por ellos mismos sus necesidades artísticas sin la intercesión de ninguna doctrina sacerdotal, la propia existencia del monopolio de los instrumentos de consagración artística, reuniendo en un mismo movimiento la desacralización de lo sagrado o la desbanalización de lo rutinizado y la sacralización del sacrilegio propia del modelo de la revolución artística.

El carácter no-programático, no institucionalizable y las tomas de posición insolentes y desapegadas de las estrategias constituyeron propiedades singulares de su revolución específica y de ningún modo algún tipo de carencia, utilizándolas como armas en lucha en la desmarcación distintiva del grupo de artistas de la generación predecesora en los planos ético y estético. A la luz de esto se comprende que el tipo y la duración de la subversión herética de las reglas vigentes del campo de Los Novísimos se diferencie con mucho de aquella anterior emprendida por el grupo Arte Nuevo en contra de los que habían sido llamados "tradicionalistas": mientras el desarrollo del grupo Arte Nuevo conduce a 
un proceso de sistematización y racionalización de la apropiación de los bienes de salvación dotando, por ejemplo a través del trabajo pedagógico de Blinder, a sus escolares de los instrumentos artísticos necesarios para la defensa de sus posiciones y la manipulación segura, continua y concertada de un capital simbólico común, la subversión de Los Novísimos, cuya ética es extraña a toda rutinización ortodoxa, se compara a "la orgía erótica y la embriaguez de la danza" y es tanto excesiva como libre, dinámica y violenta: es a causa de su propia naturaleza que su aparición no puede ser sino efímera y el tiempo de su dominación el preciso para reanimar tumultuosamente la creencia y el valor del juego.

Los efectos de las estrategias de Los Novísimos se extendieron a todos los espacios de este microcosmos en formación, y la acumulación inicial de capital simbólico permitió a artistas que pudieron y supieron aprehender el mensaje herético reinvertir los beneficios en itinerarios que recorrerían luego ya de manera individual. La puesta a prueba del par campo-habitus y la liberación del arte de divinidades por los medios de la historización fueron las condiciones de posibilidad para establecer estos hallazgos, trabajo que, también, permite hablar, a partir de ahora, de un "campo artístico paraguayo" en sentido bourdieusiano (y no como declamación retórica): la definición absolutamente propia de Los Novísimos del artista volcado a la producción artística pura y sin intermediaciones, la ética indiferente a los sueños humanistas y las exigencias circunstanciales de la política, el carácter dinámico y libre de violentar las reglas estéticas vigentes y cuestionar el monopolio de la legitimación legítima como, además y consecuentemente a esto, la disposición anti-institucionalista del grupo, han modificado con amplitud, durante casi toda la segunda mitad de la década del 6o, toda la estructura de las posiciones y el espacio de los posibles, provocando una revolución simbólica específica que, a modo de un estallido, terminaría transformando el campo artístico paraguayo con sus efectos.

\section{REFERENCIAS}

Alsina, A., Artecona, M., Argüello, M. et al. (1964). Declaración de los artistas, escritores e intelectuales de la República. Sobre la libertad de creación. La tribuna, 7.

Blinder, O. (2004). Olga Blinder. Una biografía / Entrevistada por Teresa Goossen. Goossen Libros.

Blinder, O. (1964). Primera exposición de novísima pintura. Alcor, (29), 12.

Blinder, O., Plá, J. y Laterza, J. (1964). Artistas y Público se Acercan / Entrevistados por Periodista. La tribuna.

Bourdieu, P. (2017). Manet. A Symbolic Revolution. Polity.

Bourdieu, P. (2015). Las reglas del arte. Génesis y estructura del campo literario. Anagrama.

Bourdieu, P. (2012). La distinción. Criterio y bases sociales del gusto. Taurus.

Bourdieu, P. (2006). Génesis y estructura del campo religioso (Alicia Gutiérrez, trad.). Relaciones, 27(108), 29-83. https://www.redalyc.org/articulo.oa?id=13710803

Careaga, E. (1964). Los jóvenes hablan de la exposición. La Bienal de Córdoba / Entrevistado por Periodista. La tribuna.

Colombino, C. (1964). Carlos Colombino y la Pintura Moderna en el Paraguay / Entrevistado por Periodista. La tribuna.

Deleuze, G. (2007). Pintura: el concepto de diagrama. Cactus.

Escobar, T. (2007). Una interpretación de las artes visuales en el Paraguay. Servilibro.

García, M. (2008). Abstracción entre Argentina y Brasil. Inscripción regional e interconexiones del Arte Concreto (19441960) Tomos I y II [Tesis doctoral, Universidad de Buenos Aires]. Filodigital-Repositorio Institucional. http:// repositorio.filo.uba.ar/handle/filodigital/1665

García, M. (2014). Hegemonies and Models of Cultural Modernization in South America: The Paraguay-Brazil Case. Art Margins, 3(1), 28-54. https://doi.org/10.1162/ARTM_a_00069

Krasniansky, B. (1975). Bernardo Krasniansky: Dar al papel su especificidad / Entrevistado por Jesús Ruiz Nestosa. $A b c$, SD7.

Nepomuceno, M. (2013). Lívio Abramo en Paraguay. Entretejiendo culturas. Don Bosco.

Nickson, A. (2011). El régimen de Stroessner (1954-1989). En, I. Telesca (coord.), Historia del Paraguay, (pp. 265-294). Taurus.

Passeron, J. (2011). El razonamiento sociológico. El espacio comparativo de las pruebas históricas. Siglo Veintiuno.

Ponton, R. (1973). Programme esthétique et accumulation de capital symbolique. L'exemple du Parnasse. Revue française de sociologie, 14(2), 202-220. https://www.jstor.org/stable/i274963

Pratt Mayans, J. A. (1964). Un joven promisorio: Pratt Mayans / Entrevistado por Periodista. La tribuna.

Quevedo, C. (2018). La travesía de Lívio Abramo: Arte, militancia y exilio. En, C. Peris (Coord.), Paraguay: Capítulos de Prosopografía Social, (pp. 117-140). Centro de Estudios Antropológicos de la Universidad Católica (CEADUC) 
Biblioteca de Estudios Paraguayos - Vol. 120.

Roa Bastos, A. (1960). Problemas de nuestra novelística II. Alcor, (9), 4-5.

Rojas, S. (2020). Las artes plásticas en Paraguay a través de la sociología de Pierre Bourdieu: Estudio de caso en torno a la aparición del grupo Los Novísimos en el año 1964 [Tesina de grado, Universidad Nacional de Asunción]

Sapiro, G. (2012). La vocación artística, entre don y don de sí (Mariana Cerviño, trad.). Trabajo y Sociedad, (19), 503-508. https://www.redalyc.org/articulo.oa?id=387334691033

Saussure, F. (2007). Curso de lingüística general. Losada.

Trinidad, Ó. (1964). Evaluación Crítica a una Exposición. Primera Muestra de Novísima Pintura Paraguaya. La tribuna. Weber, M. (1992). Economía y Sociedad. Fondo de Cultura Económica.

\section{AUTOR}

Sergio Rojas. Licenciado en Sociología por la Universidad Nacional de Asunción.

\section{CONFLICTO DE INTERESES}

Ningún conflicto de interés posible.

\section{FINANCIAMIENTO}

El artículo no presenta asistencia financiera de partes externas.

\section{AGRADECIMIENTO}

$\mathrm{N} / \mathrm{A}$

\section{ACLARACIÓN}

El artículo presenta una serie de hallazgos de la tesina de grado de sociología, Rojas (2020), defendida en febrero de 2020 en la Facultad de Ciencias Sociales, Universidad Nacional de Asunción. 